\title{
Significance of reciprocal ST depression in acute myocardial infarction: a study of 258 patients treated by thrombolysis
}

Department of Cardiology, London Chest Hospital, London

RN Stevenson,

AD Timmis

Cardiology, Newham General Hospital, London

K Ranjadayalan V Umachandran

Correspondence to Dr Robert Stevenson, Department of Cardiology, London Chest Hospital, Bonner Road, London E2 9JX.

Accepted for publication 9 October 1992

Robert N Stevenson, Kulasegaram Ranjadayalan, Velaitham Umachandran, Adam D Timmis

\begin{abstract}
Objective-To investigate the clinical significance of reciprocal ST depression on the presenting electrocardiogram in patients with acute myocardial infarction treated by thrombolysis.
\end{abstract}

Design-A prospective cohort analytical study.

Setting-A London district general hospital.

Subjects-Two hundred and fifty eight consecutive patients with acute myocardial infarction treated with thrombolysis.

Interventions-All patients underwent treadmill stress testing after a mean (SEM) of 10 (3) days; 200 patients (78\%) were referred for coronary arteriography at 30 (16) days.

Main outcome measures-Relation between reciprocal ST depression at presentation and several endpoints: time from start of chest pain to hospital presentation, electrocardiographic changes during early treadmill stress testing, presence of multivessel coronary disease, and clinical outcome in terms of recurrent ischaemic events (death, reinfarction, and unstable angina) during a 10 (range six to 12) month follow up.

Results-Presentation was generally early, but in this group of patients reciprocal ST depression was significantly related to the time from the start of symptoms, those with reciprocal change presenting on average one hour earlier than those without. Although reciprocal change on the presenting electrocardiogram was weakly associated with ST depression on treadmill stress testing, it was not indicative of remote ischaemia as a result of multivessel coronary disease or high grade collateralisation of the infarct related artery. There was no association between reciprocal change and the incidence of recurrent ischaemic events.

Conclusion-Reciprocal ST depression on the presenting electrocardiogram seems to be a benign electrical phenomenon related to the time from the start of symptoms. It does not necessarily predict an adverse prognosis in patients treated by thrombolysis.

(Br Heart f 1993;69:211-214)

In acute myocardial infarction, ST elevation is often accompanied by reciprocal ST depression remote from the infarct site but the clinical significance of this finding remains uncertain. It may be a benign electrical phenomenon, ${ }^{1}$ or alternatively an indication of remote ischaemia associated with an adverse prognosis. ${ }^{2-4}$ If reciprocal ST change in acute myocardial infarction is associated with an adverse prognosis, this may be favourably influenced by thrombolytic treatment. In our study, therefore, we have reevaluated the relation between reciprocal ST change, coronary anatomy, and clinical outcome in a cohort of patients with acute myocardial infarction all of whom received thrombolytic treatment.

\section{Patients and methods}

PATIENT SELECTION

This was a prospective study of 258 consecutive patients who presented to Newham General Hospital and received intravenous thrombolytic treatment for acute myocardial infarction. The diagnosis of acute myocardial infarction was based on any two of three criteria: typical chest pain, $>0.1 \mathrm{mV} \mathrm{ST}$ elevation in at least one standard or two adjacent precordial leads, rise in serum creatine kinase to $>400 \mathrm{IU} / \mathrm{l}$. Most were treated with $1.5 \mathrm{mil}-$ lion IU of streptokinase infused over one hour but, because we were participating in the multi centre Third International Study of Infarct Survival (ISIS 3) Study during part of the recruitment period, 40 patients were treated with either streptokinase $(1.5$ million IU infused over one hour), duteplase (100 mg infused over four hours), or anistreplase (30 IU injected over three minutes), depending on the randomisation. Specific inclusion criteria were: (a) acute myocardial infarction as defined earlier; (b) treatment with a thrombolytic agent; (c) uncomplicated hospital courses without ongoing chest pain, electrical instability, or heart failure; (d) ability to perform a symptom limited treadmill stress test; (e) no electrocardiographic abnormalities preventing interpretation of the stress test (left bundle branch block, paced rhythms, digoxin induced ST/T changes). At the time of this study, coronary arteriography was offered to all patients under the age of 70 as routine clinical practice, and was performed in 200. Reasons for not proceeding to arteriography in the remaining 58 patients included age $>70(n=31)$, and refusal to give consent $(n=15)$; in the remainder the reason was not recorded. 
Table 1 Clinical and angiographic details of study population

\begin{tabular}{lc}
\hline & Clinical details $(\mathrm{n}=258)$ \\
Age & $56 \cdot 9(\mathrm{range} 33-79)$ years \\
Sex & $201(78 \%)$ men \\
Infarct site: & 130 \\
$\quad$ Anterior & 128 \\
Inferior & $205(79 \%)$ \\
Q wave infarct & Angiographic details $(\mathrm{n}=200)$ \\
\multicolumn{2}{l}{$\begin{array}{l}\text { Single vessel disease } \\
\text { Two vessel disease }\end{array}$} \\
Three vessel disease & 66 \\
\hline
\end{tabular}

\section{INTERPRETATION OF THE ADMISSION ELECTROCARDIOGRAMS}

The time from the start of symptoms to the recording of the first electrocardiogram (performed in the accident and emergency department) was recorded in each case. Reciprocal ST depression on the presenting electrocardiogram was defined as $>0.1 \mathrm{mV}$ ST depression in one or more adjacent leads in a territory remote from the site of concurrent ST elevation (that is: inferior infarction-leads 1, aVL, V1-V4; anterior infarction-leads $2,3, \mathrm{aVF}$ ).

\section{EXERCISE TESTING}

Symptom limited treadmill testing (modified Bruce protocol) was performed before or soon after discharge from hospital, 10 (range seven to 21) days after infarction. Patients were exercised for three minute stages at progressively increasing workloads. The 12 lead electrocardiogram was recorded before exercise, at the end of each stage, and at peak exercise. Significant ST depression during the stress test was defined as horizontal or down sloping ST depression $>0.1 \mathrm{mV}$ below the resting level measured $0.08 \mathrm{~s}$ after the $\mathrm{J}$ point. Significant ST elevation was defined as $>0.1$ $\mathrm{mV}$ elevation above the resting level measured at the $\mathrm{J}$ point.

Exercise induced ST depression was considered to be reciprocal if associated with concurrent ST elevation in another territory-invariably the infarct related leads. Otherwise ST depression was classified as isolated.

\section{CARDIAC CATHETERISATION}

Patients underwent coronary arteriography and single plane (right anterior oblique) left ventriculography within two to four weeks of discharge from hospital. Written, informed consent was obtained in every case. Multiple projections of the coronary arteries were recorded on cinefilm and were reviewed by two experienced observers who were blind to the results of the admission electrocardiogram and treadmill stress tests. Significant stenosis was defined as $>50 \%$ luminal narrowing, assessed by visual inspection, occurring in any of the three major coronary vessels or their major branches. Collateral circulation was assessed by a previously defined method that grades collaterals according to the extent to which the epicardial arterial segment distal to the infarct related lesion is retrogradely opacified: $0=$ no collateral vessels visible, $1=$ collateral vessels visible, $2=<50 \%$ opacification of distal segment, $3=>50 \%$ opacification of distal segment. ${ }^{5}$ Collateral scores of 2 or 3 were considered to represent high grade collateralisation.

STATISTICAL ANALYSIS

Averaged values are expressed as mean (SEM). Normal distribution could not be $\stackrel{7}{c}$ assumed for the times to presentation and these data were analysed with the Mann- $\stackrel{0}{+}$ Whitney $U$ test. The distribution of discrete variables between groups was compared by the $\chi^{2}$ test.

\section{Results}

The 258 patients underwent treadmill stress testing after 10 (3) days, and 200 of them $(78 \%)$ were referred for coronary arteriography after 30 (16) days. Table 1 shows the clinical and angiographic details.

RECIPROCAL CHANGE AND TIME TO PRESENTATION

All patients presented with regional ST elevation and, of these, $148(57 \%)$ had reciprocal ST depression. Reciprocal change was more common with inferior than anterior infarction (74\% v 42\%; p < 0.0001). Presentation was generally early (mean time to presentation: $4.06(0.20) \mathrm{h})$, but in this group of patients reciprocal change was significantly related to the time from the start of symptoms, patients with reciprocal change presenting on average one hour earlier than those without $(3.71$ $(0.26) v 4.69(0.34) \mathrm{h} ; \mathrm{p}<0.01)$.

\section{RECIPROCAL CHANGE AND CORONARY} ANATOMY

Table 2 shows that reciprocal change on the admission electrocardiogram had no relation with angiographic findings at cardiac catheterisation: importantly it was unrelated to either multivessel disease or high grade collateralisation (grade 2-3) of the infarct related artery.

\section{RECIPROCAL CHANGE AND RECURRENT} ISCHAEMIC EVENTS

Table 3 shows the follow up data available for $N$ all patients 6 to 12 months after discharge $\underset{\omega}{N}$ from hospital. During this period 41 patients 0 had acute ischaemic events: unstable angina 6 $(n=15)$, reinfarction $(n=21)$, sudden death $\Phi$ $(n=5)$. These data represent an event rate $?$ (hard events) of $16 \%$. A further 23 patients

Table 2 Relation between reciprocal change on the admission electrocardiogram and presence of multivessel disease and high grade collateralisation of the infarct related coronary artery

\begin{tabular}{|c|c|c|c|}
\hline & $\begin{array}{l}\text { No reciprocal } \\
\text { change } \\
(n=90) \\
n(\%)\end{array}$ & $\begin{array}{l}\begin{array}{l}\text { Reciprocal } \\
\text { change }\end{array} \\
n(\%)\end{array}$ & $\begin{array}{r}(n=110) \\
p \text { value }\end{array}$ \\
\hline $\begin{array}{l}\text { Multivessel disease } \\
(\mathrm{n}=104)\end{array}$ & $46(51)$ & $58(53)$ & NS \\
\hline $\begin{array}{l}\text { Collaterals } \\
\quad(n=56)\end{array}$ & $23(26)$ & $33(30)$ & NS \\
\hline
\end{tabular}


Table 3 Relation between reciprocal change on the admission electrocardiogram and recurrent ischaemic events

\begin{tabular}{clll}
\hline & $\begin{array}{l}\text { No reciprocal } \\
\text { change } \\
(n=110) \\
n(\%)\end{array}$ & $\begin{array}{l}\text { Reciprocal } \\
\text { change } \\
(n=148) \\
n(\%)\end{array}$ & p value \\
\hline $\begin{array}{c}\text { Hard event } \\
(\mathrm{n}=41)\end{array}$ & $15(14)$ & $26(18)$ & NS \\
$\begin{array}{c}\text { Any event } \\
(\mathrm{n}=64)\end{array}$ & $27(25)$ & $37(25)$ & NS \\
\hline
\end{tabular}

Hard event is unstable angina, reinfarction, or death; any event is hard event or revascularisation.

underwent revascularisation for clinical reasons increasing the event rate (any events) to $25 \%$. There was no association between reciprocal change on the initial electrocardiogram and recurrent ischaemic events whether or not revascularisation was regarded as an end point.

\section{RECIPROCAL CHANGE AND ST DEPRESSION ON} TREADMILL STRESS TESTING

Table 4 shows that patients with reciprocal change on the admission electrocardiogram were more likely to have exercise induced ST depression than those without reciprocal change $(57 \%$ v $42 \%$; $p<0.02)$. Exercise induced ST depression was categorised as reciprocal when it was associated with exercise induced ST elevation in the infarct related leads, but was otherwise regarded as isolated. Interestingly reciprocal change on the initial electrocardiogram was not associated with reciprocal ST depression on treadmill testing, but it was associated with isolated ST depression. Thus $33 \%$ of patients with reciprocal change on the initial electrocardiogram had isolated ST depression during exercise testing compared with only $20 \%$ of patients without reciprocal change $(33 \% v 20 \%$; p < 0.05).

\section{Discussion}

The significance of reciprocal ST depression on the electrocardiogram during the early stages of myocardial infarction remains uncertain. Opinion is divided as to whether it is a sign of multivessel coronary disease and an adverse prognosis, ${ }^{2-4}$ or a benign electrical phenomenon. ${ }^{1}$ Our results support the benign view in that, in this group of patients presenting early after myocardial infarction, reciprocal change was unrelated to both multivessel

Table 4 Relation between reciprocal change on the admission electrocardiogram (columns) and exercise $S T$ depression (STd) on treadmill stress testing

\begin{tabular}{llll}
\hline & $\begin{array}{l}\text { No reciprocal } \\
\text { change } \\
(n=106) \\
n(\%)\end{array}$ & $\begin{array}{l}\text { Reciprocal } \\
\text { change } \\
(n=147) \\
n(\%)\end{array}$ & p value \\
\hline $\begin{array}{l}\text { Exercise Std } \\
\quad \text { (All) }\end{array}$ & $44(42)$ & $84(57)$ & 0.02 \\
$\begin{array}{l}\text { Exercise Std } \\
\text { (Reciprocal) }\end{array}$ & $21(20)$ & $36(24)$ & NS \\
$\begin{array}{c}\text { Exercise Std } \\
\text { (Isolated) }\end{array}$ & $21(20)$ & $48(33)$ & 0.05 \\
\hline
\end{tabular}

coronary disease and recurrent ischaemic events.

We have shown that reciprocal ST depression is more common in inferior infarction, and in patients presenting very early after the start of chest pain. The association of reciprocal change with inferior infarction accords with previous work ${ }^{6}$, and presumably reflects the number of leads available remote from the site of infarction in which reciprocal change can be seen. The finding that reciprocal change is associated with early presentation has not been reported before, possibly because the time to hospital presentation was not usually a subject of interest before thrombolytic treatment became widely used. Thus none of the previous studies of reciprocal change during acute myocardial infarction that were carried out in the prethrombolytic era, commented on time to hospital presentation. Evidence against reciprocal change as a benign electrical phenomenon, is that it is not always evident despite the presence of considerable ST elevation in the infarct leads. Our finding, however, that reciprocal change occurs very early in the time course of myocardial infarction suggests that in many cases it resolves before admission to hospital despite persistent ST elevation in the zone of infarction. It is noteworthy, that the patients in our study presented relatively early after the start of symptoms and therefore our findings may not necessarily apply to patients presenting much later.

The data from this study provide no support for the view that reciprocal ST depression is a sign of ischaemia remote from the infarct site. Thus there was no association between reciprocal change and multivessel coronary disease, and no evidence to suggest coronary steal resulting from high grade collateralisation of the occluded infarct related artery. Previous studies suggesting an association between reciprocal change and multivessel disease were conducted with few patients, many of whom were selected for coronary arteriography on the grounds of ongoing symptoms or an abnormal treadmill stress test. $^{2-489}$ Odemuyiwa $e t$ al, however, found no relation between reciprocal change and multivessel disease in eighty four patients all of whom underwent coronary arteriography without apparent selection bias. ${ }^{6}$ Selection bias was also largely avoided in our study because coronary arteriography was performed regardless of symptoms in accordance with our clinical policy. The finding that reciprocal change was not associated with multivessel disease is supported by studies of controlled coronary occlusion during angioplasty in which reciprocal ST depression is no more common in patients with multivessel disease than those with single vessel disease, ${ }^{10}$ and is not associated with remote regional left ventricular wall motion abnormality. ${ }^{11}$ Furthermore, in our study reciprocal change did not appear to reflect remote ischaemia caused by coronary steal related to collateral flow to the occluded infarct related artery. This mechanism cannot be totaly discounted, 
however, as the simple angiographic assessment of collateralisation used in this study may not be a true reflection of haemodynamically important collateral flow. Finally, it has been suggested that in patients with reciprocal change, occlusion of the infarct related artery may result in remote ischaemia by compromising important collateral flow to the myocardium remote from the zone of infarction, ${ }^{12}$ although this possibility could not be assessed in the present study.

Some studies carried out in the prethrombolytic era suggested an association between the presence of reciprocal change and an adverse prognosis, ${ }^{2-413}$ although in only two were the data statistically significant. ${ }^{313}$ All were limited by their small sample sizes, and "soft" end points such as angina after infarction, left ventricular failure, and the requirement for coronary bypass surgery. Metcalfe $e t$ $a l$ in a retrospective study of 260 patients after infarction, showed a significantly higher mortality during long-term follow up among those with reciprocal change on the admission electrocardiogram. ${ }^{14}$ Moreover, the presence of reciprocal change was associated with higher than average concentrations of serum creatine kinase suggesting that these patients had more extensive infarctions. The results of our own prospective study in which all patients received thrombolytic treatment show no association between reciprocal change and an adverse prognosis in terms of recurrent ischaemic events. The Thrombolysis and Angioplasty in Myocardial Infarction Study Group studied 289 patients with inferior myocardial infarction, and showed that those with reciprocal precordial ST depression had lower ejection fractions and regional wall motion scores that those without, despite reperfusion treatment with thrombolysis and rescue angioplasty. ${ }^{15}$ Apart from a higher incidence of atrioventricular block in patients with reciprocal change, there was no significant difference in outcome, and no association between reciprocal change and concomitant disease in the left anterior descending artery. Thus it seems that, although reciprocal change may be more common in large infarcts, its presence in patients receiving thrombolysis does not necessarily indicate an adverse prognosis. This may in part be explained by the finding that reciprocal change is more common in patients who present very early, and therefore obtain maximum benefit from early thrombolysis.

The weak association between reciprocal change on the presenting electrocardiogram and exercise induced ST depression has been noted before, although the clinical significance of this finding may have been exaggerated. ${ }^{379}$ The unexpected finding that reciprocal change is associated with isolated rather than reciprocal ST depression on treadmill tests has not been reported before. We have already shown that reciprocal ST depression (ST depression associated with ST elevation in the infarct related leads) on treadmill tests is associated with extensive $Q$ wave infarction and non-patency of the infarct related coronary artery. ${ }^{16}$ By contrast, isolated exercise induced ST depression is indicative of ischaemia and is weakly predictive of a patent infarct related coronary artery. Thus patients with reciprocal change on the admission electrocardiogram are more likely $\underline{\underline{\sigma}}$ to have an ischaemic response to exercise $I$ than those without, possibly because regional left ventricular function is better preserved as a result of early presentation and thrombolysis.

To conclude, in acute myocardial infarction, reciprocal ST depression on the admission electrocardiogram is common in patients who present very early after the start of symptoms. In the early stages of acute myocardial $\%$ infarction, the phenomenon does not seem to $\overrightarrow{0}$ indicate remote ischaemia as a result of multivessel coronary disease or high grade collateralisation of the infarct related artery. Furthermore, in the thrombolytic era at least, reciprocal change is not necessarily associated with an adverse prognosis.

1 Mirvis DM. Physiologic bases for anterior ST segment depression in patients with acute inferior wall myocardial infarction. Am Heart $\Im$ 1988;116:1308-22.

2 Jennings K, Reid D, Julian DG. "Reciprocal depression of the ST segment in acute myocardial infarction. $B M \mathcal{F} \stackrel{\supset}{\supset}$ 1983;287:634-7

3 Akhras F, Upward J, Jackson G. Reciprocal change in ST $\overrightarrow{0}$ segment in acute myocardial infarction: correlation $\omega$ with findings on exercise electrocardiography and coronary angiography. $B M \mathcal{F}$ 1985;290:1931-4.

4 Salcedo JR, Baird MG, Chambers RJ, Beanlands DS. Significance of reciprocal ST segment depression in anterior precordial leads in acute inferior myocardial infarction: Concomitant left anterior descending coronary artery disease? $A m \mathcal{F}$ Cardiol 1981;48:1003-7.

5 Rentrop KP, Cohen M, Blanke H, Phillips RA. Changes in collateral channel filling immediately after controlled coronary artery occlusion by an angioplasty balloon in human subjects. $\mathcal{F} \mathrm{Am}$ Coll Cardiol 1985;5:587-92.

6 Odemuyiwa U, Peart I, Albers C, Hall R. Reciprocal ST depression in acute myocardial infarction. Br Heart $\mathcal{F}$ 番 1985;54:479-83.

7 Tzivoni D, Chenzbraun A, Keren A, et al. Reciprocal electrocardiographic changes in acute myocardial infarction. Am $\mathcal{F}$ Cardiol 1985;56:23-6.

8 Strasberg B, Pinchas A, Barbash GI, et al. Importance of reciprocal ST segment depression in leads V5 and V6 as an indicator of disease of the left anterior descending coronary artery in acute inferior wall myocardial infarction. Br Heart f 1990;63:339-41.

9 Murray DP, Tan LB, Salih M, Weissberg P, Murray RG, Littler WA. Reciprocal change, exercise induced ST segment depression and coronary anatomy: are they related in the post-infarct patient? Clin Sci 1988;74: I related

10 Quyyumi AA, Crake T, Rubens MB, Levy RD, Rickards AF, Fox KM. Importance of "reciprocal" electrocardio- N graphic changes during occlusion of left anterior descending coronary artery. Studies during percuta- $N$ neous transluminal coronary angioplasty. Lancet 1862;i:347-50.

11 Norrell MS, Lyons JP, Gardener JE, Layton CA, Balcon O R. Significance of "reciprocal" ST segment depression: left ventriculographic observations during left anterior 6 descending coronary angioplasty. $\mathcal{f}$ Am Coll Cardiol $\bar{\varnothing}$ 1989;13:1270-4.

12 Schuster EH, Bulkley BH. Ischemia at a distance after : acute myocardial infarction: a cause of early postinfarction angina. Circulation 1980;62:509-15.

13 Shah PK, Pilcher M, Maddahi J, Peter T, Singh BN, Swan HJC. Noninvasive identification of a high risk subset of patients with acute inferior myocardial infarcsubset of patients with acute inferior myocardial infarc- 2

tion. Am Cardiol 1980,46:915-21.

Metcalfe MJ, Rawles JM, Shirreffs C, Jennings K. Six year follow-up of a consecutive series of patients presenting to the coronary care unit with acute chest pain: prognostic importance of the electrocardiogram. Br Heart $\mathcal{f}$ 1990;63:267-72.

15 Bates ER, Clemmensen PM, Calif RM, et al. and the Thrombolysis and Angioplasty in Myocardial Infarction (TAMI) Study Group. Precordial ST segment depression predicts a worse prognosis in inferior infarction despite reperfusion therapy. I Am Coll Cardiol 1990; 16:1538-44.

16 Stevenson RN, Umachandran V, Ranjadayalan K, Timmis AD. Significance of reciprocal ST depression with acute infarction treated by thrombolysis [abstract]. Br Heart $\mathcal{F}$ 1992;68:104. 